\title{
A Quantum-Chemical DFT Approach to Elucidation of the Chirality Transfer Mechanism of the Enantioselective Suzuki-Miyaura Cross-Coupling Reaction
}

\author{
Radomir Jasiński, ${ }^{1}$ Oleg M. Demchuk, ${ }^{2}$ and Dmytro Babyuk ${ }^{3}$ \\ ${ }^{1}$ Institute of Organic Chemistry and Technology, Cracow University of Technology, Warszawska 24, 31-155 Cracow, Poland \\ ${ }^{2}$ Department of Organic Chemistry, Maria Curie-Skłodowska University, 33 Gliniana Street, 20-614 Lublin, Poland \\ ${ }^{3}$ Institute of Biology, Chemistry and Bioresources, Chernivtsi National University, 2 Kotsyubynsky Str., Chernivtsi 58012, Ukraine \\ Correspondence should be addressed to Oleg M. Demchuk; oleh.demchuk@umcs.lublin.pl
}

Received 15 February 2017; Accepted 27 March 2017; Published 25 May 2017

Academic Editor: Maria F. Carvalho

Copyright ( 2017 Radomir Jasiński et al. This is an open access article distributed under the Creative Commons Attribution License, which permits unrestricted use, distribution, and reproduction in any medium, provided the original work is properly cited.

The DFT calculations of the simplified model of the asymmetric Suzuki-Miyaura coupling reaction were performed at the M062x/LANL2DZ theory level at first. It was found that enantioselective reactions mediated by the palladium complexes of chiral $C, P$-ligands follow a four-stage mechanism similar to that proposed previously as one of the most credible mechanisms. It should be underlined that the presence of substituents in the substrates and the chiral ligand at ortho positions determines the energies of possible diastereoisomeric transition states and intermediates in initial reaction steps. This suggests that, in practice, a sharp selection of theoretically possible paths of chirality transfer from the catalyst to the product should have a place and, therefore, the absolute configuration of the formed atropisomeric product is defined and can be predicted.

\section{Introduction}

Palladium mediated cross-coupling reactions constitute one of the main synthetic tools for creation of new carbon-carbon bonds $[1,2]$. The carbon atoms of all types of hybridisation, possessing a variety of leaving or nonpreactivated groups, can be connected together if properly designed catalysts are used. Excellent chemical yields are usually observed in a majority of cross-coupling reactions, even those run under mild conditions. The notable progress observed during the last decade in medicinal [3-6], material [7-10], and green chemistry $[11,12]$ makes the issue of efficient asymmetric synthesis of drug precursors, functional materials, and fine chemicals significantly urgent, since chiral nonracemic compounds have already found wide industrial application. Among all cross-coupling reactions, only the asymmetric Heck coupling (and its several modifications, e.g., the Fujiwara-Moritani reaction and oxidative boron Heck-type reactions) is well developed [13-15]. At the same time, the enantioselective approach to other coupling reactions still remains challenging [16-18]. Without clear understanding of the mechanism of chirality transfer from the chiral catalyst to the product, a rational design of an efficient catalyst, tailored for a given enantioselective coupling reaction, remains not possible and consequent testing of a large quantity of similar ligands will be a costly alternative $[18,19]$.

Herein, we are going to present the results of our computational finding of the origin of asymmetric induction in cross-coupling reactions. Since aryl-aryl bond forming cross-couplings are mechanistically quite similar, in our studies on enantioselective coupling we concentrated on the Suzuki-Miyaura reaction, which is usually applied as a method of first choice. The mechanics of the nonstereocontrolled Suzuki-Miyaura (and a few other couplings) reaction catalysed by complexes of nonchelating monophosphines has been studied in detail (Scheme 1) [20-29] and can be extrapolated to reactions catalysed by transition metal complexes of different types and to stereoselective transformations. At 




SCHEME 1: Generally accepted mechanism of SM reaction.

the same time, the nature of chirality transfer still remains unclear and only general intuitive mechanistic considerations have been published to date [30].

In highly enantioselective Suzuki-Miyaura couplings, palladium complexes of significantly sterically hindered ligands are usually used [16, 18]. Accurate computer calculations of such large complexes need an extremely large computational cost. Additionally, for palladium catalysts based on regular bidentate ligands (e.g., BINAP (I) [31]) and monodentate ligands (e.g., oligo-aryl phosphine (II) and oligo-aryl phosphonites (III) [32]) (Figure 1), several different models of solvation and mono- and biscomplexation should be evaluated [23, 33-36]. Obviously, a discovery of subtle interactions influencing the absolute configuration of the product formed in the reaction mediated by interconverting complexes of large phosphorus ligands cannot be accurate because of many entropic issues that certainly take place but are difficult to handle. In the case of less bulky and especially bisphosphine chelating ligands, different types of 14-electron $\mathrm{PdL}_{2}$ complexes have been postulated as active catalysts, and corresponding products of the oxidative addition reactions to such complexes have been characterised [37-40]. Thus, we decided to concentrate on highly efficient, also in asymmetric SM reactions, chiral ligands of the $C, P$-type of complexation represented by KenPhos and similar ones (IV) [30, 41, 42], MeO-MOP (V) [43], and BisNap-Phos (VI) [44] (Figure 1). These ligands form well-defined bidentate mono-P-liganded $\operatorname{Pd}(0)$ species [45-48] with the structures formally corresponding to the 12-electron Pd-P(III) active catalysts of the $\mathrm{SM}$ reaction (Scheme 2, AC). The active catalyst is extremely reactive and readily undergoes oxidative addition reaction with aromatic halides to form intermediates with a welldefined structure I1 $[49,50]$.
Even such simple complexes are spatially developed and complicated enough not to allow accurate computation of their fine properties and stereochemical behaviour if the entire structure is considered. Nevertheless, in the case of catalytic systems in which substrates and ligands do not bear bending function groups (whose interaction can control the geometry of preordination intermediates) and the catalyst is a complex of the C,P-ligand, the geometry of the intermediates is less sensitive to the substitution pattern and several coordinal simplifications can be applied. Thus, the geometry of the palladium complexes will remain almost the same if the cyclohexyl groups situated on the phosphorus atom are replaced with methyl groups. Also, the biaryl core of the ligand can be simplified to formally chiral $6,2^{\prime}$ dimethylbiphenyl, and eventually 2-bromotoluene and 2tolylboronic acid can be selected as the simplest substrates of the enantioselective cross-coupling reaction (Scheme 3 ). This significant simplification allows accurate DFT calculations of the entire reactions leading to the chiral (but with low racemisation energy) product [51].

With the objective of gaining insight into the origin of stereoselectivity of the selected reacting system run in aqueous media, we decided to perform DFT simulations of possible reaction paths to confirm its actual molecular mechanism and find conditions influencing the configuration of the chiral product formed.

\section{Results and Discussion}

2.1. Computational Procedure. The quantum-chemical calculations reported in this paper were performed on "Zeus" and "Prometheus" supercomputers in the "Cyfronet" computational centre in Cracow. The M062x [52] functional 
<smiles>c1ccc(-c2ccc3ccccc3c2-c2cccc3ccccc23)cc1</smiles><smiles>Cc1ccc2ccccc2c1-c1c(-c2ccccc2)ccc2ccccc12</smiles>

IV<smiles>Cc1ccc(-c2c(-c3ccc(C)cc3)c(-c3ccc(C)cc3)c(-c3ccccc3Cl)c(-c3ccc(C)cc3)c2-c2ccc(C)cc2)cc1</smiles><smiles>COc1ccc2ccccc2c1-c1c(-c2ccccc2)ccc2ccccc12</smiles>

$\mathrm{v}$<smiles>CCCCc1cc2ccccc2c(OC)c1-c1c(OC)ccc2ccccc12</smiles>

VI

FIGURE 1: Selected chiral ligands used in SM reactions.<smiles>CPCc1ccccc1-c1ccccc1</smiles>

PC

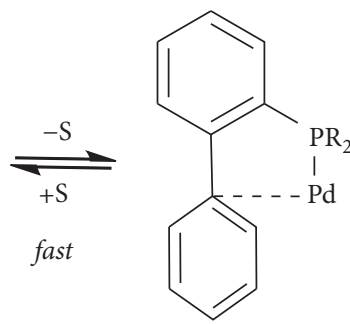<smiles>C=C</smiles>

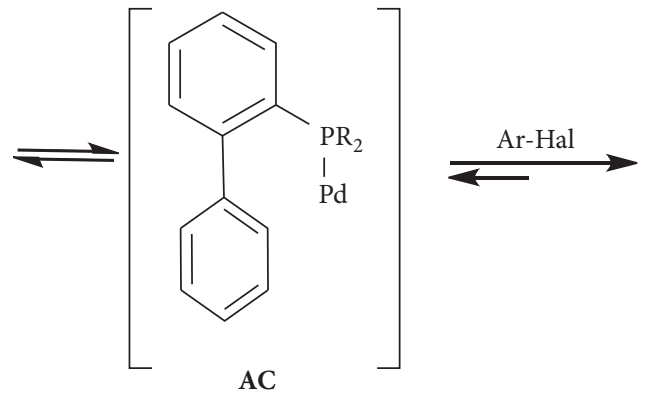

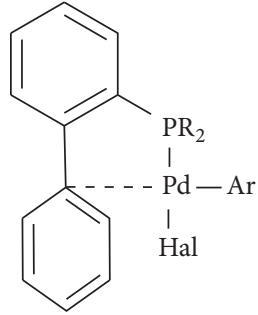

I1

$\mathrm{S}=$ weakly coordinating solvent

SCHeme 2: Models of C,P-complexation: precatalyst: PC, active catalyst: AC, and intermediate: I1.

implemented in the GAUSSIAN 09 package [53] was used. This functional is dedicated for precise energetic considerations $[52,54]$ and has been recently applied for simulation of the reaction paths of several different reactions, including arylic systems [55], phosphorus compounds [56], and halogenide-derivatives $[57,58]$. Critical structures are fully optimized using basis sets: 6-31G(d) for $\mathrm{H}, \mathrm{C}, \mathrm{O}, \mathrm{B}, \mathrm{Br}$, and $\mathrm{P}$, as well as LANL2DZ with one $\mathrm{f}$ function for $\mathrm{Pd}$ and without pseudopotential. Identical basis sets have been recently used for quantitative description of similar processes involving similar chemical molecules [21]. For elementary reaction, in which anionic species are involved, calculations using basis set with one diffusion function were performed in parallel to procedure described above. It was found that in this way practically identical critical structures were obtained. Next, we have reoptimized key, representative transition states using M06 functional, in which HF exchange contribution is significantly lower, than on the case of M062x functional. It has been found that obtained structures are very similar to those derived from M062x calculations. Thus, we concluded that the applied theory level should be recognized as wholly adequate to solve the presented problem. 


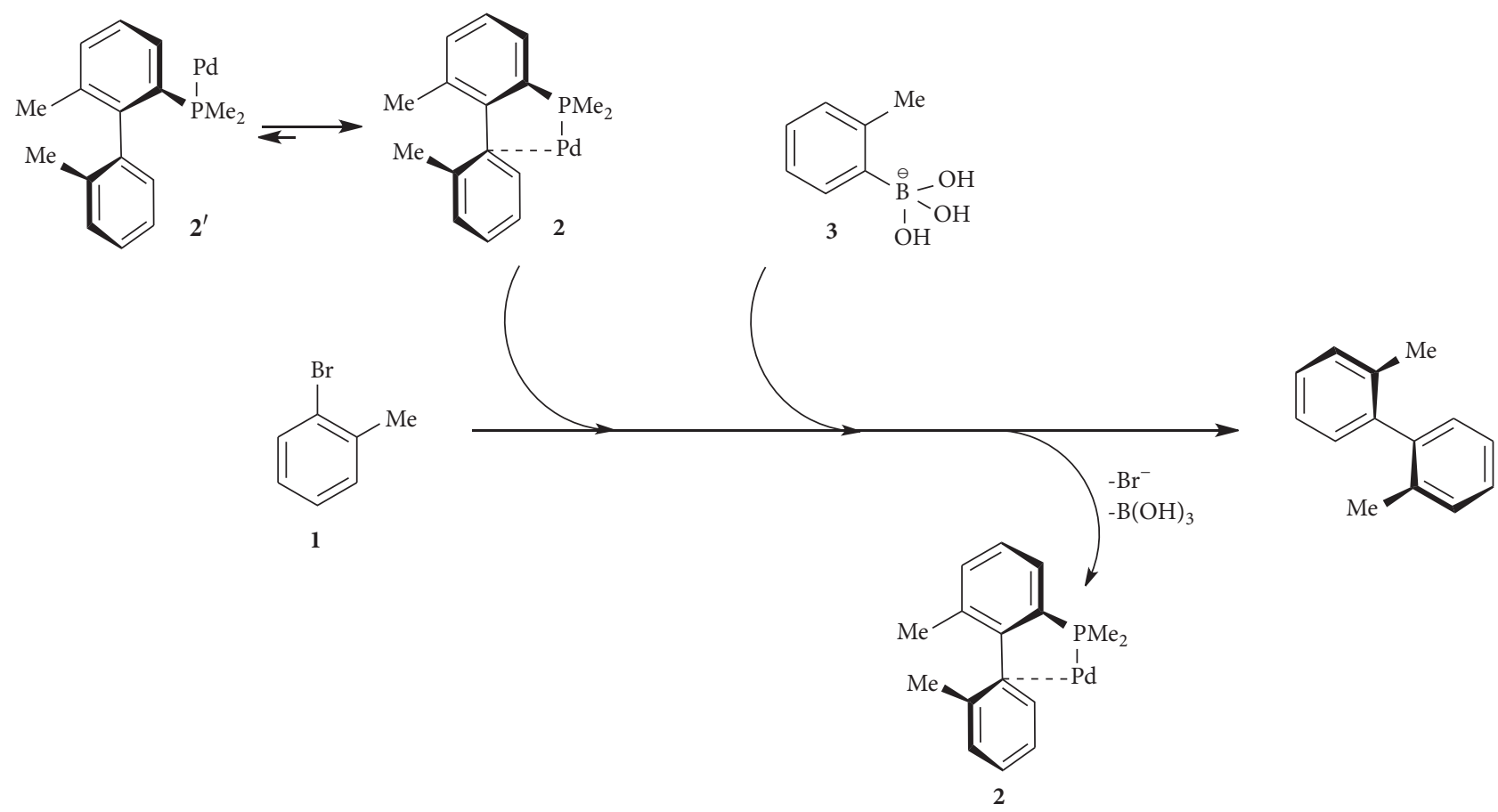

Scheme 3: Model coupling reaction.

The Berny algorithm was applied for optimization of the structure of the reactants and the reaction products. First-order saddle points were localized using the QST2 procedure. Stationary points were characterised by frequency calculations. All reactants and products had positive Hessian matrices. All transition states showed only one negative eigenvalue in their diagonalized Hessian matrices, and their associated eigenvectors were confirmed to correspond to the motion along the reaction coordinate under (IRC) calculations performed to connect previously computed transition structures (TS) with suitable minima. For the calculations of the solvent effect (presence of water), the polarizable continuum model (PCM) [59], in which the cavity is created via a series of overlapping spheres, was used. For optimized structures, thermochemical data for the temperature $T=$ $298 \mathrm{~K}$ and pressure $p=1 \mathrm{~atm}$ were computed using vibrational analysis data.

2.2. Catalyst Activation. According to the widely accepted concept, monoliganded coordinatively unsaturated and unstable 12-electron palladium complexes, which are formed by dissociation of bulky diphosphine (or similar) complexes, can be an active catalysts of the cross-coupling reaction (Scheme 1). In the case of $C, P$-complexes, 12-electron active catalyst is formed by dissociation of the $\mathrm{Pd}-\mathrm{C}$ coordination bond (Scheme 2), and the energy of this process may influence the reaction rate. Several products of the oxidative addition possessing only one ligand at the phosphorus atom have been obtained and characterised [35, 36, 50, 60-62]. Thus, we decided to shed light on the energetic stability of the model chiral catalytic complex 2 (Scheme 3). The
M062x calculations showed that the complex with "cyclic" conformation (2) is more than $5.5 \mathrm{kcal} / \mathrm{mol}$ stable than the competitive structure with "extended" conformation $\left(2^{\prime}\right)$. This is a consequence of failure of the Pd-C complexation effect in $2^{\prime}$.

Subsequently, we performed a similar study for a similar fluorinated system illustrated in Figure 2 (structures $\mathbf{2 a}$ and $2 \mathbf{a}^{\prime}$ ), in which the aryl system has a relatively more $\pi$ deficient nature. In both cases, we reached a qualitatively similar conclusion. Thus, it can be assumed that the $\mathrm{C}$ Pd complexation effect is important for stabilization of the palladium-ligand complex irrespective of the nature of the substitution of aryl moiety.

A possible way to evaluate the $\mathrm{Pd}-\mathrm{C}$ binding energy is "homolytic dissociation" (Figure 3) of the optimized complex structure into frozen fragments (no optimization is done for them). The uM062x/LANL2DZ calculation shows that the following fragmentation requires energy $\left(E_{1}\right)$ equal to $129.97 \mathrm{kcal} / \mathrm{mol}$ (Figure 3(a)). It includes $\mathrm{Pd}-\mathrm{Ar}$ and $\mathrm{Ar}-$ Ar binding energies. To exclude the Ar-Ar energy, similar fragmentation is needed (Figure 3(b)). In this case, the dissociation energy $\left(E_{2}\right)$ is equal to $124.16 \mathrm{kcal} / \mathrm{mol}$. The difference $E_{1}-E_{2}=5.81 \mathrm{kcal} / \mathrm{mol}$ is due to $\mathrm{Pd}-\mathrm{C}$ binding, which is close to the value derived by rotating the Ar-Ar group leading to $2^{\prime}$. The total stabilization due to the presence of the Pd atom, calculated similarly by removal of the Pd atom from the complex, is $32.36 \mathrm{kcal} / \mathrm{mol}$. Similarly, the energy of $\mathrm{Pd}-\mathrm{P}$ binding was calculated to be equal to $15.16 \mathrm{kcal} / \mathrm{mol}$. Since the Pd-C interaction is significantly weaker than the $\mathrm{Pd}-\mathrm{P}$ one, we expect dissociation of Pd-P within the catalytic cycle. 


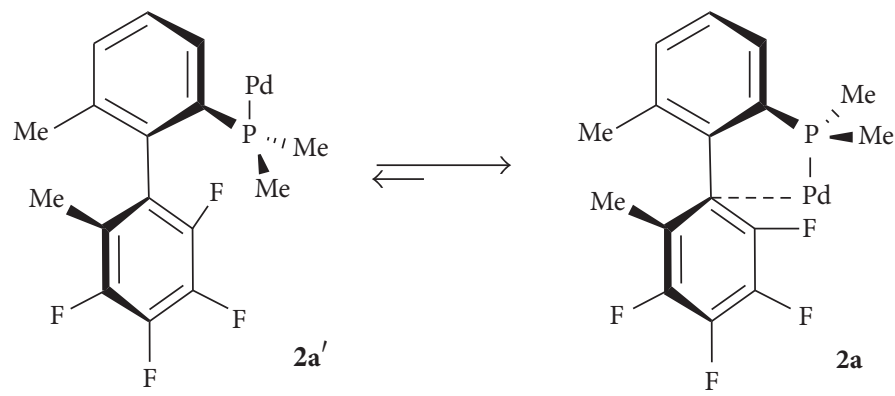

Figure 2: "Cyclic" (2a) and "extended" (2a') conformations of the fluorinated $C, P$-complex.<smiles>CCN(c1ccccc1C)c1ccccc1C</smiles><smiles>Cc1cccc(C)c1-c1ccccc1[N+](C)(C)C</smiles>
<smiles>CCP(C)c1cccc(C)c1</smiles><smiles>Cc1ccccc1</smiles>

(a)<smiles></smiles>

(b)

FIgURE 3: "Homolytic dissociation" of C,P-complex 2 (a) and respective phosphine ligand (b).

2.3. Oxidative Addition Step. Next, we carried out a detailed study of the mechanism of model cross-coupling involving catalyst 2 . The first stage includes formation of an adduct of 2bromotoluene with catalyst 2 (Scheme 4 ). Since the palladium atom is shielded with the aromatic ring, the attack of the 2-bromotoluene molecule on the $\mathrm{Pd}$ atom may take place only from directions that are not shielded by the ligand. In particular, four competitive paths were found, during which the following processes take place: (1) creation of a $\mathrm{Pd}-\mathrm{Br}$ bond in the direction of the axis of the P-Pd coordination bond (paths leading to adducts $\mathbf{5} \mathbf{a}$ and $\mathbf{5 b}$, resp.) or (2) creation of a $\mathrm{Pd}-\mathrm{Br}$ bond in the direction perpendicular to the axis of the P-Pd bond (paths leading to adducts $5 \mathrm{c}$ and 5d, resp.).

Thermodynamical analysis shows that in the case of all the considered paths the reaction equilibrium is evidently shifted towards the valley of the products. However, $5 \mathbf{c}$ and 5d are relatively more stable. Free Gibbs enthalpy of formation is below $29 \mathrm{kcal} / \mathrm{mol}$ for these compounds and equal to ca. $19 \mathrm{kcal} / \mathrm{mol}$ for products $\mathbf{5 a}$ and $\mathbf{5 b}$. Generally, thermodynamic stability of theoretically possible products should be ordered as follows: $5 c>5 d \gg 5 b>5 a$.

Analyses of the kinetic aspects of the directions of substrate transformations indicate that the reaction proceeding according to path $\mathbf{C}$ is evidently kinetically favoured $\left(\Delta G^{\neq}\right.$ $=0.2 \mathrm{kcal} / \mathrm{mol})$. Other paths should be considered as unfavourable or outright forbidden from the kinetic point of view (Figure 4).

The theoretically possible transformations between isomeric adducts $\mathbf{5 a - d}$ have also been analysed. It was found that under reaction conditions all of these transitions should be considered as forbidden from the kinetic point of view, since in all of the considered cases the interconversion energy was higher than $30 \mathrm{kcal} / \mathrm{mol}$.

Thus, it should be assumed that an isomer that is formed according to path $\mathbf{C}$ can be treated as a generally favoured structure for a wide group of reactions. This product enters the subsequent addition stages.

Two new bonds are formed within the transition state of the $1+2 \rightarrow 5$ c reaction $-\mathrm{Pd}-\mathrm{Br}(r=3.246 \AA)$ and $\mathrm{Pd}-\mathrm{C}_{(\mathrm{Ar})}$ 
<smiles>Cc1ccccc1-c1c(C)cccc1P(C)C</smiles><smiles>Cc1ccccc1Br</smiles><smiles>Cc1ccccc1-c1c(C)cccc1P(C)(Br)(Br)[P+](C)c1ccccc1C</smiles>

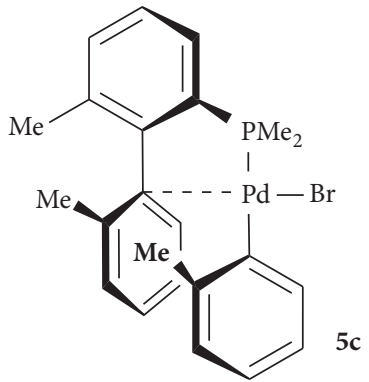

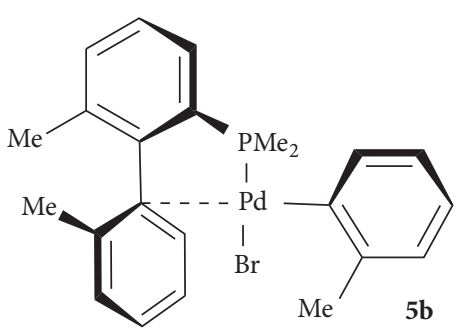<smiles>Cc1ccccc1P([P+](c1ccccc1C)c1c(C)cccc1C)C(C)(Br)Br</smiles>

Scheme 4: Theoretically possible product of the oxidative addition step.

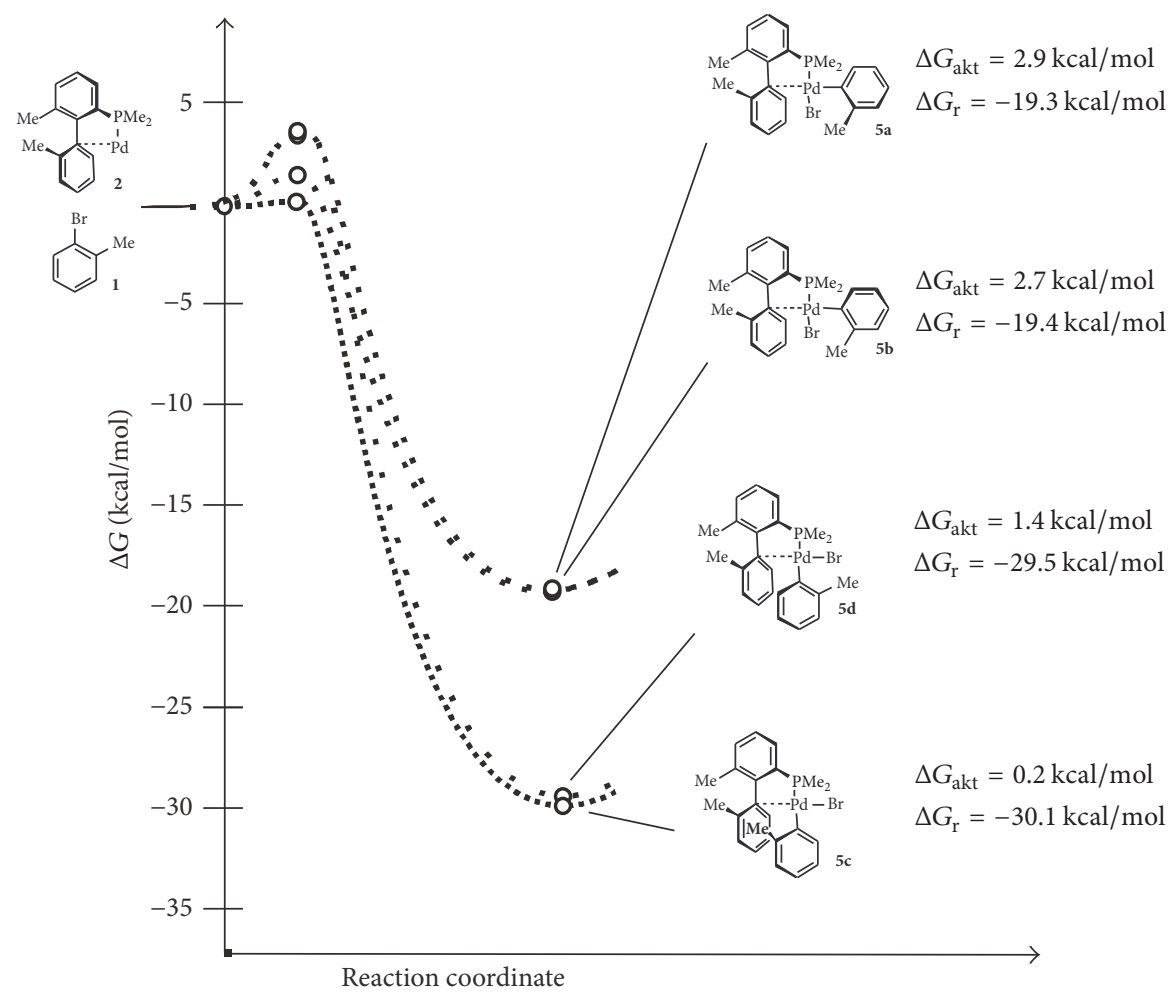

FIGURE 4: Energy profiles for competitive channels of oxidative addition reaction.

$(r=2.305 \AA$ ). This is accompanied by the breakage of the

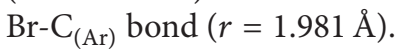

In addition to our theoretical studies, the relevance of structure $5 \mathrm{c}$ can be confirmed by comparison of our theoretical considerations with the $\mathrm{X}$-ray structures of similar $C, P$ palladium complexes (VII) $[63,64]$ and, additionally, with the same structure optimized using the M062x/LANL2DZ theory level in simulated presence of water $\left(\mathbf{V I I}^{\prime}\right)$, as shown in Figure 5 and Table 1. It was found that the key angles and interatomic distances were rather similar.

2.4. Transmetallation Step. The different possibilities of transmetallation reaction that may take place in the second stage of the asymmetric SM reaction were assessed. It has 

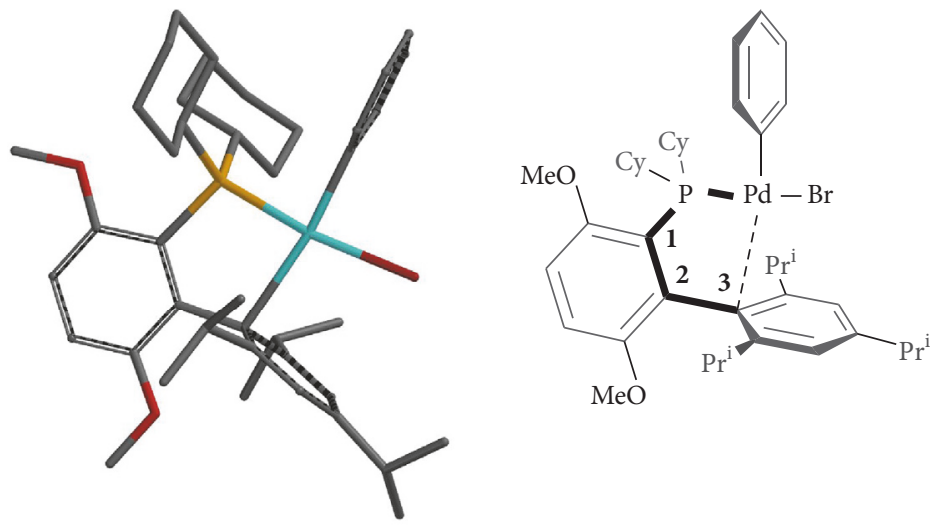

FIgURE 5: X-ray structure of complex VII [63].

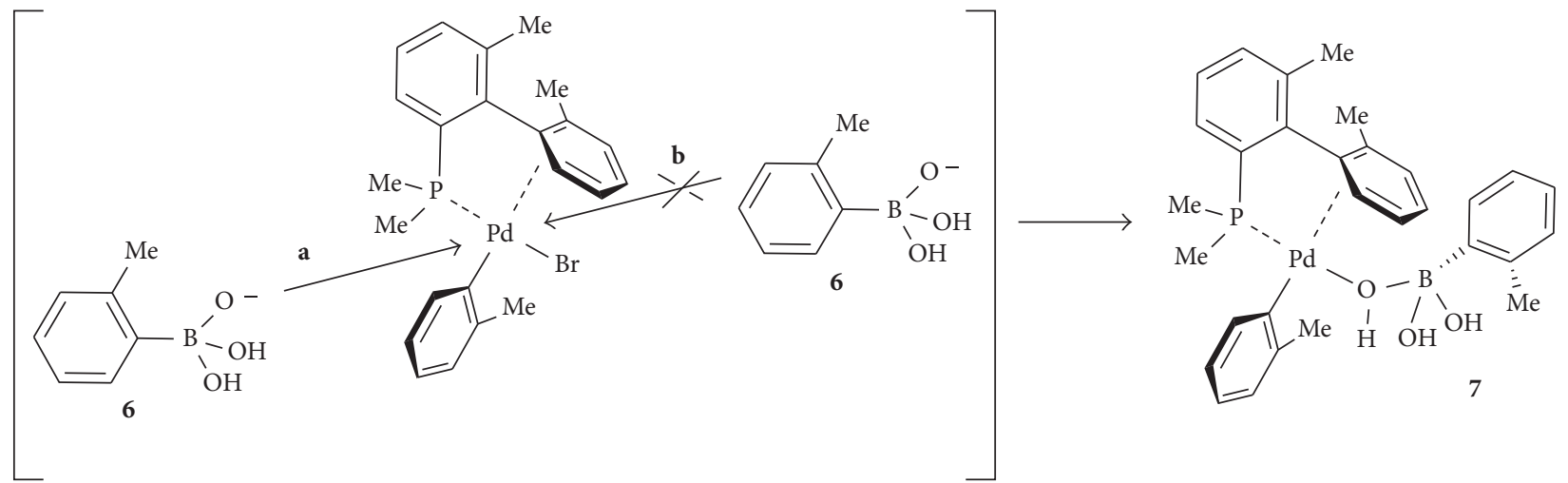

Scheme 5: Two possible paths of transmetallation.

TABLE 1: Comparison of the key geometrical parameters of complexes $\mathbf{5 c}$, VII, and $\mathbf{V I I}^{\prime}$.

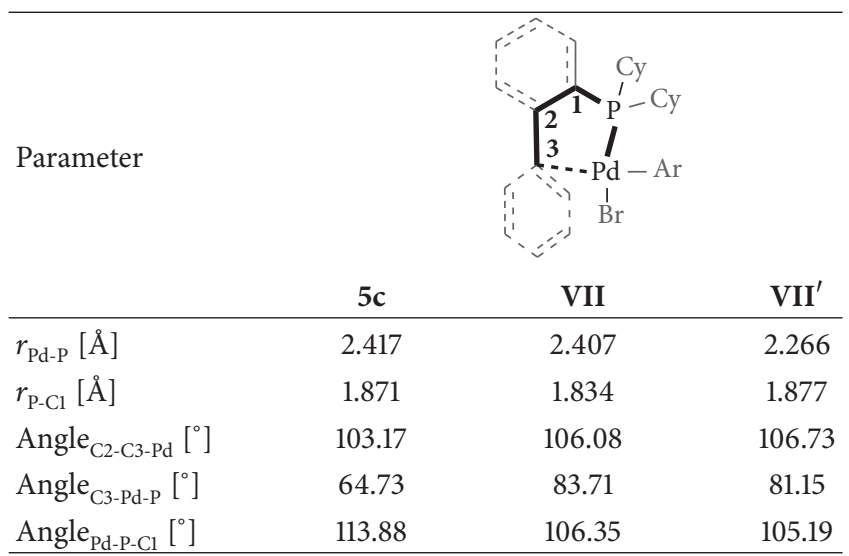

been shown that the transmetallation step in a typical SM coupling reaction does not proceed without the nucleophilic additive, which enhances the electron density at the boron atom through its coordination and formation of boron-ate adduct $[20,21,24,65,66]$. In an aqueous solution of inorganic bases, the role of this nucleophile may be played by the hydroxyl anion. Thus, the second stage of the reaction includes substitution of the bromine atom with the $\mathrm{ArB}(\mathrm{OH})_{3}{ }^{-}$anion (6) (Scheme 5). The alternative reaction pathways involving the participation of neutral $\mathrm{ArB}(\mathrm{OH})_{2}$ or Pd-OH species were not favourable.

Attack of molecule 6 on the Pd atom is possible only when both methyl groups bound to phenyl rings are turned opposite to the anion approach trajectory, attack according to the "a" trajectory (Scheme 5). All attempts at finding transition stages related to the theoretically possible process of the approach of molecule $\mathbf{6}$ to the Pd atom along the "b" trajectory failed.

During the approach to the Pd atom, the $\mathbf{6}$ anion may theoretically assume various orientations. Two paths of such an approach were found, differing in the orientation of the methyl group within the anion. However, only one of these should be considered kinetically permitted. The activation barrier of the transition is $4.1 \mathrm{kcal} / \mathrm{mol}$. This process takes place via the TS2 transition state (Figures 6 and 7). The PdBr bond $(r=2.696 \AA)$ of this state becomes gradually more loose, and at the same time a new Pd-O bond $(r=2.178 \AA)$ is formed. Conversion of the reacting system along the reaction coordinate leads directly from TS2 to the product 7.

During the transmetallation stage, a boric acid molecule is eliminated, with simultaneous formation of a bond between 

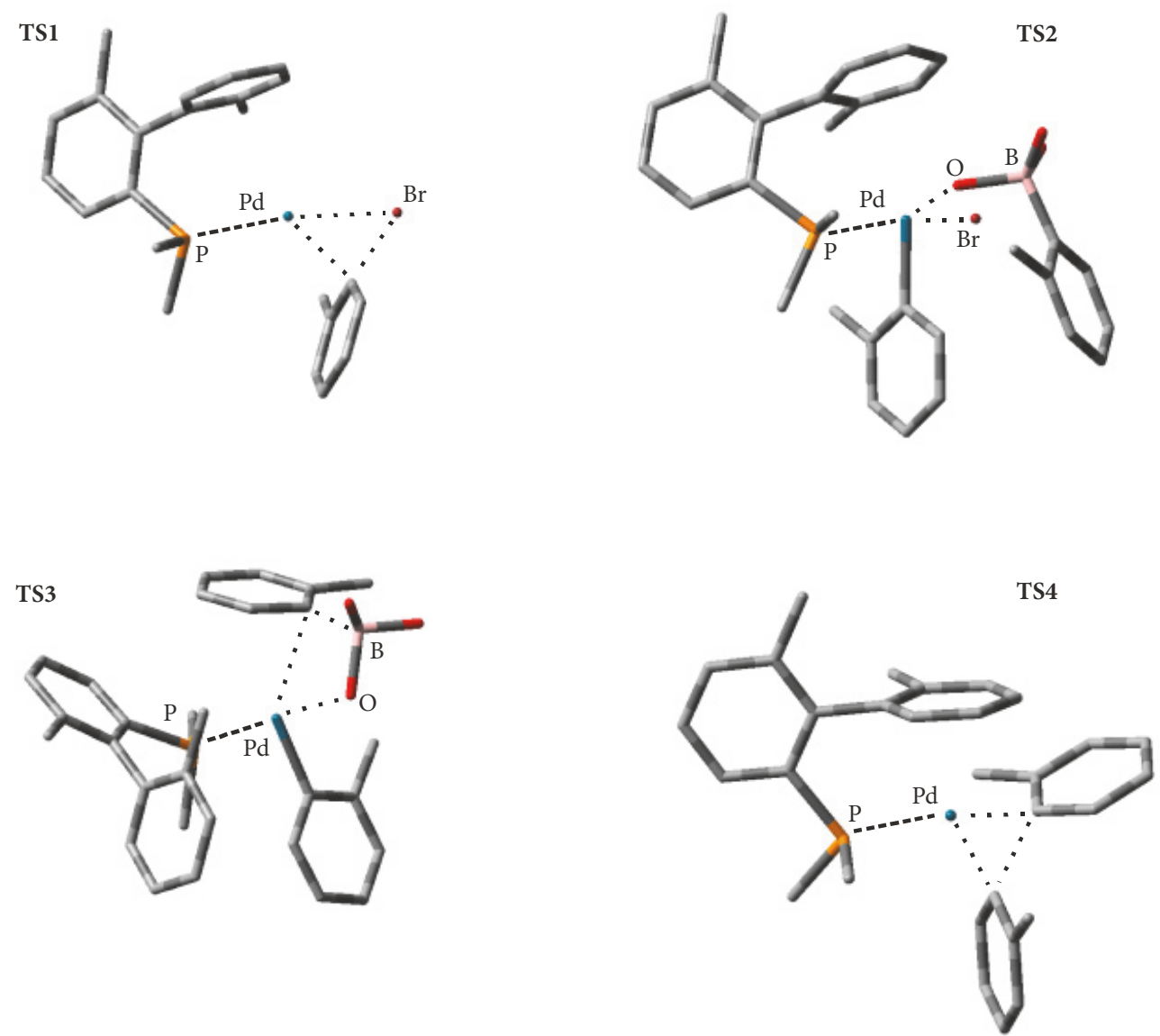

FIgURE 6: Views of transition states according to DFT calculations.

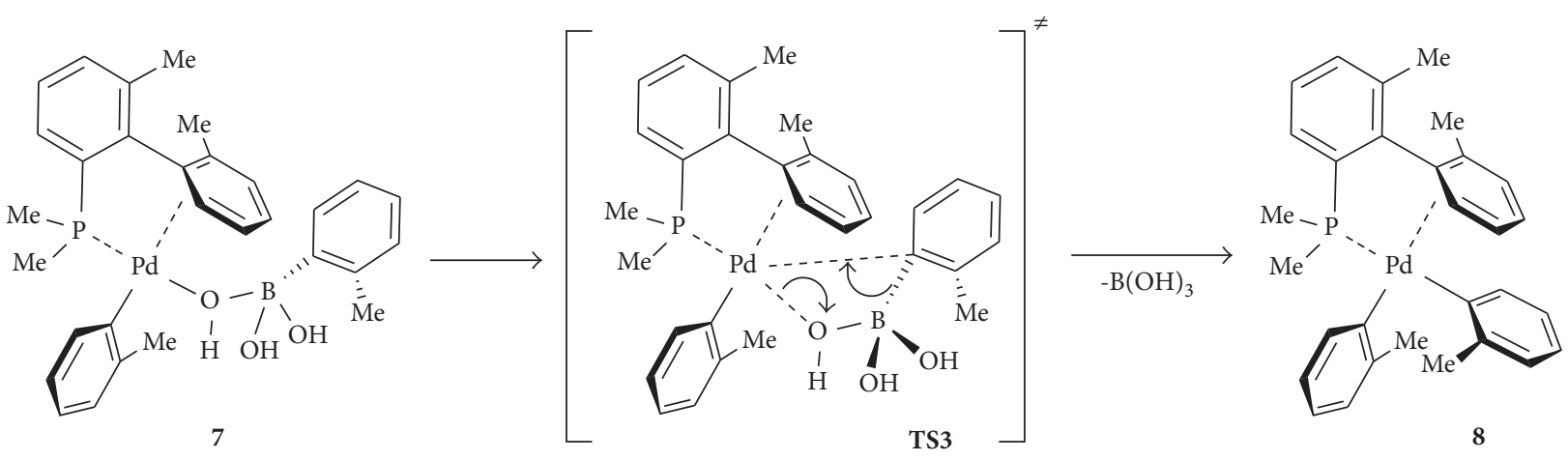

SCHEME 6: Formation of the transition stage TS3.

the palladium atom and the carbon atom of the phenyl ring introduced into the reacting system from the $\operatorname{ArB}(\mathrm{OH})_{3}{ }^{-}$ molecule.

This transformation takes place through the transition state TS3 (Scheme 6) and requires the activation barrier $\Delta G^{\neq}$ $=7.1 \mathrm{kcal} / \mathrm{mol}$ to be overcome. As a result of a synchronous, circular electron shift within TS3, the bonds between the palladium atom and the oxygen atom $(r=2.151 \AA)$ and between the boron atom and the carbon atom in position 1 of the phenyl ring become ruptured $(r=1.632 \AA)$. This is accompanied by formation of a new $\sigma$-bond between the phenyl ring and the palladium atom $(r=2.676 \AA)$. It leads to formation of compound $\mathbf{8}$.

2.5. The Reductive Elimination Stage. The last reductive elimination stage takes place via the TS4 transition state and requires an activation barrier which is equal to $8.6 \mathrm{kcal} / \mathrm{mol}$. Thermodynamic factors, on the other hand, favour practically an irreversible shift of equilibrium towards the product, as free enthalpy of the system decreases by over $25 \mathrm{kcal} / \mathrm{mol}$ as 




FIGURE 7: Free Gibbs energy profile for energetically preferred reaction path according to DFT calculations.

a result of this elementary reaction. Notably, the previously proposed possibility of the rotation of aryls around the Pd-Ar and $\mathrm{Pd}-\mathrm{Ar}^{\prime}$ bonds in 8 [30], which may yield products with an opposite absolute configuration, has a rotation barrier greater than $15 \mathrm{kcal} / \mathrm{mol}$. Thus, this could be considered as almost forbidden and slow; hence the product configuration change at this stage of the reaction cannot be significant.

\section{Conclusions}

The DFT calculations performed with the simplified reaction model indicate that the palladium-catalysed process of asymmetric cross-coupling should take place according to a four-stage mechanism. It should also be stated that the presence of substituents in the ortho positions of the substrates (aryl bromide and borate anion) determines a sharp selection of theoretically possible reaction directions. This means that, in practice, the conversion of the reacting system should take place according to a single reaction path only. Because rupture of existing bonds takes place simultaneously with formation of new bonds within all transition states, the entire process should take place stereoselectively and lead predominantly to one atropisomeric form. This assumption makes the task of rationalisation of the stereochemical outcome of the reaction much simpler, since only one, that is, the first reaction stage, should be analysed to predict the absolute configuration of a majority of formed biaryl products. 


\section{Conflicts of Interest}

The authors declare that they have no conflicts of interest.

\section{Acknowledgments}

The generous allocation of computing time by the Regional Computer Centre "Cyfronet" in Cracow (Grant no. MNiSW/ Zeus_lokalnie/PK/009/2013) and support from the Polish National Science Centre (NCN Grant no. 2012/05/B/ST5/ 00362) are gratefully acknowledged.

\section{References}

[1] A. J. Burke and C. S. Marques, Eds., Catalytic Arylation Methods: From the Academic Lab to Industrial Processes, Wiley-VCH, Weinheim, Germany, 2015.

[2] L.-N. He, E. Lokteva, C. Mota, and P. Tundo, Eds., Chemistry Beyond Chlorine, Springer, Basel, Switzerland, 2016.

[3] G.-Q. Lin, Q.-D. You, and J.-F. Cheng, Eds., Chiral Drugs: Chemistry and Biological Action, John Wiley \& Sons, Hoboken, NJ, USA, 2011.

[4] L. A. Nguyen, H. He, and C. Pham-Huy, "Chiral drugs: an overview," International Journal of Biomedical Science, vol. 2, pp. 85-100, 2006.

[5] J. McConathy and M. J. Owens, "Stereochemistry in drug action," The Primary Care Companion to the Journal of Clinical Psychiatry, vol. 5, no. 2, pp. 70-73, 2003.

[6] N. Chhabra, M. Aseri, and D. Padmanabhan, "A review of drug isomerism and its significance," International Journal of Applied and Basic Medical Research, vol. 3, no. 1, pp. 16-18, 2013.

[7] L. Pu, Ed., 1,1'-Binaphthyl-Based Chiral Materials: Our Journey, World Scientific, Hackensack, NJ, USA, 2010.

[8] B. L. Feringa and W. R. Browne, Eds., Molecular Switches, WileyVCH, Weinheim, Germany, 2011.

[9] J. W. Goodby, P. J. Collings, T. Kato, C. Tschierske, H. Gleeson, and P. Raynes, Eds., Handbook of Liquid Crystals, Wiley-VCH, Weinheim, Germany, 2nd edition, 2014.

[10] N. Katsonis, E. Lacaze, and A. Ferrarini, "Controlling chirality with helix inversion in cholesteric liquid crystals," Journal of Materials Chemistry, vol. 22, no. 15, pp. 7088-7097, 2012.

[11] A. Patti, "Green approaches to asymmetric catalytic synthesis," in Springer Briefs in Molecular Science Green Chemistry for Sustainability, S. K. Sharma, Ed., Springer, Dordrecht, Netherlands, 2011.

[12] V. K. Ahluwalia and M. Kidwai, New Trends in Green Chemistry, Kluwer Academic, New Delhi, India, 2004.

[13] M. Oestreich, The Mizoroki-Heck Reaction, Wiley, Chichester, UK, 2009.

[14] D. Mc Cartney and P. J. Guiry, “The asymmetric heck and related reactions," Chemical Society Reviews, vol. 40, no. 10, pp. 51225150, 2011.

[15] C. Wu and J. Zhou, "Asymmetric intermolecular heck reaction of aryl halides," Journal of the American Chemical Society, vol. 136, no. 2, pp. 650-652, 2014.

[16] O. M. Demchuk, K. Kapłon, A. Kącka, and K. M. Pietrusiewicz, "The utilization of chiral phosphorus ligands in atroposelective cross-coupling reactions," Phosphorus, Sulfur and Silicon and the Related Elements, vol. 191, no. 2, pp. 180-200, 2016.
[17] H. Yang, X. Yang, and W. Tang, "Transition-metal catalyzed asymmetric carbon-carbon cross-coupling with chiral ligands," Tetrahedron, vol. 72, no. 41, pp. 6143-6174, 2016.

[18] A. Chatterjee, H. Mallin, J. Klehr et al., "An enantioselective artificial Suzukiase based on the biotin-streptavidin technology," Chemical Science, vol. 7, no. 1, pp. 673-677, 2016.

[19] Y. Akai, L. Konnert, T. Yamamoto, and M. Suginome, "Asymmetric Suzuki-Miyaura cross-coupling of 1-bromo-2-naphthoates using the helically chiral polymer ligand PQXphos," Chemical Communications, vol. 51, no. 33, pp. 7211-7214, 2015.

[20] S. A. Patil, C.-M. Weng, P.-C. Huang, and F.-E. Hong, "Convenient and efficient Suzuki-Miyaura cross-coupling reactions catalyzed by palladium complexes containing N,N,O-tridentate ligands," Tetrahedron, vol. 65, no. 15, pp. 2889-2897, 2009.

[21] A. A. C. Braga, N. H. Morgon, G. Ujaque, A. Lledós, and F. Maseras, "Computational study of the transmetalation process in the Suzuki-Miyaura cross-coupling of aryls," Journal of Organometallic Chemistry, vol. 691, no. 21, pp. 4459-4466, 2006.

[22] L.-P. Chen and H.-P. Chen, "DFT Investigation on the mechanism of $\operatorname{Pd}(0)$ catalyzed sonogashira coupling reaction," Jiegou Huaxue, vol. 30, no. 9, pp. 1289-1297, 2011.

[23] W.-J. Sun, W. Chu, L.-J. Yu, and C.-F. Jiang, "Ligand size effect on PdLn oxidative addition with aryl bromide: A DFT study," Chinese Journal of Chemical Physics, vol. 23, no. 2, pp. 175-179, 2010.

[24] C. Sicre, A. A. C. Braga, F. Maseras, and M. M. Cid, "Mechanistic insights into the transmetalation step of a Suzuki-Miyaura reaction of 2(4)-bromopyridines: characterization of an intermediate," Tetrahedron, vol. 64, no. 30-31, pp. 7437-7443, 2008.

[25] Q. Liu, Y. Lan, J. Liu, G. Li, Y.-D. Wu, and A. Lei, "Revealing a second transmetalation step in the Negishi coupling and its competition with reductive elimination: improvement in the interpretation of the mechanism of biaryl syntheses," Journal of the American Chemical Society, vol. 131, no. 29, pp. 10201-10210, 2009.

[26] T. Mondal, S. De, B. Maity, and D. Koley, "Exploring the oxidative-addition pathways of phenyl chloride in the presence of pd(II) abnormal n-heterocyclic carbene complexes: A DFT study," Chemistry, vol. 22, no. 44, pp. 15778-15790, 2016.

[27] H. Xie, T. Fan, Q. Lei, and W. Fang, "New progress in theoretical studies on palladium-catalyzed $\mathrm{C}-\mathrm{C}$ bond-forming reaction mechanisms," Science China Chemistry, vol. 59, pp. 1432-1447, 2016.

[28] S. Raoufmoghaddam, S. Mannathan, A. J. Minnaard, J. G. De Vries, and J. N. H. Reek, "Palladium(0)/NHC-catalyzed reductive heck reaction of enones: a detailed mechanistic study," Chemistry-A European Journal, vol. 21, no. 51, pp. 18811-18820, 2015.

[29] S. Sakaki, Y.-Y. Ohnishi, and H. Sato, "Theoretical and computational studies of organometallic reactions: Successful or not?" Chemical Record, vol. 10, no. 1, pp. 29-45, 2010.

[30] A. Herrbach, A. Marinetti, O. Baudoin, D. Guénard, and F. Guéritte, "Asymmetric synthesis of an axially chiral antimitotic biaryl via an atropo-enantioselective Suzuki cross-coupling," Journal of Organic Chemistry, vol. 68, no. 12, pp. 4897-4905, 2003.

[31] G. Bringmann, S. Rüdenauer, T. Bruhn, L. Benson, and R. Brun, "Total synthesis of the antimalarial naphthylisoquinoline alkaloid 5-epi-4'-O-demethylancistrobertsonine $\mathrm{C}$ by asymmetric Suzuki cross-coupling," Tetrahedron, vol. 64, no. 23, pp. 55635568, 2008. 
[32] T. Kamei, A. H. Sato, and T. Iwasawa, "Asymmetric SuzukiMiyaura cross-coupling of aryl chlorides with enhancement of reaction time and catalyst turnover," Tetrahedron Letters, vol. 52, no. 21, pp. 2638-2641, 2011.

[33] C. Amatore and F. Pflüger, "Mechanism of oxidative addition of palladium $(0)$ with aromatic iodides in toluene, monitored at ultramicroelectrodes," Organometallics, vol. 9, no. 8, pp. 22762282, 1990.

[34] J.-F. Fauvarque, F. Pflüger, and M. Troupel, "Kinetics of oxidative addition of zerovalent palladium to aromatic iodides," Journal of Organometallic Chemistry, vol. 208, no. 3, pp. 419-427, 1981.

[35] J. F. Hartwig and F. Paul, "Oxidative addition of aryl bromide after dissociation of phosphine from a two-coordinate palladium(0) complex, bis(tri-o-tolylphosphine)palladium(0)," Journal of the American Chemical Society, vol. 117, no. 19, pp. 5373-5374, 1995.

[36] E. Galardon, S. Ramdeehul, J. M. Brown, A. Cowley, K. K. Hii, and A. Jutand, "Profound steric control of reactivity in aryl halide addition to bisphosphane palladium(0) complexes," Angewandte Chemie-International Edition, vol. 41, no. 10, pp. 1760-1763, 2002.

[37] N. Miyaura and S. L. Buchwald, "Cross-coupling reactions a practical guide," in Topics in Current Chemistry, p. 248, Springer, Berlin, Germany, 2002.

[38] L. M. Alcazar-Roman and J. F. Hartwig, "Mechanistic studies on oxidative addition of aryl halides and triflates to $\mathrm{Pd}(\mathrm{BINAP}) 2$ and structural characterization of the product from aryl triflate addition in the presence of amine," Organometallics, vol. 21, no. 3, pp. 491-502, 2002.

[39] S. Shekhar, P. Ryberg, and J. F. Hartwig, "Oxidative addition of phenyl bromide to Pd(BINAP) vs Pd(BINAP)(amine). Evidence for addition to Pd(BINAP)," Organic Letters, vol. 8, no. 5, pp. 851-854, 2006.

[40] M. Portnoy and D. Milstein, "Mechanism of aryl chloride oxidative addition to chelated palladium $(0)$ complexes," Organometallics, vol. 12, no. 5, pp. 1665-1673, 1993.

[41] Š. Vyskočil, M. Smrčina, V. Hanuš, M. Polášek, and P. Kočovský, "Derivatives of 2-amino-2' -diphenylphosphino-1,1'-binaphthyl (MAP) and their application in asymmetric palladium(0)catalyzed allylic substitution," Journal of Organic Chemistry, vol. 63, no. 22, pp. 7738-7748, 1998.

[42] Š. Vyskočil, M. Smrčina, and P. Kočovský, "Synthesis of 2-amino-2'-diphenylphosphino-1,1'-binaphthyl (MAP) and its accelerating effect on the $\mathrm{Pd}(0)$-catalyzed $\mathrm{N}$-arylation," Tetrahedron Letters, vol. 39, no. 50, pp. 9289-9292, 1998.

[43] T. Hayashi, "Chiral monodentate phosphine ligand MOP for transition-metal-catalyzed asymmetric reactions," Accounts of Chemical Research, vol. 33, no. 6, pp. 354-362, 2000.

[44] O. M. Demchuk, K. Kielar, and K. M. Pietrusiewicz, "Rational design of novel ligands for environmentally benign crosscoupling reactions," Pure and Applied Chemistry, vol. 83, no. 3, pp. 633-644, 2011.

[45] U. Christmann, R. Vilar, A. J. P. White, and D. J. Williams, "Synthesis of two novel dinuclear palladium(I) complexes and studies of their catalytic activity in amination reactions," Chemical Communications, vol. 10, no. 11, pp. 1294-1295, 2004.

[46] T. E. Barder, S. D. Walker, J. R. Martinelli, and S. L. Buchwald, "Catalysts for Suzuki-Miyaura coupling processes: scope and studies of the effect of ligand structure," Journal of the American Chemical Society, vol. 127, no. 13, pp. 4685-4696, 2005.

[47] T. Iwasawa, T. Komano, A. Tajima et al., "Phosphines having a 2,3,4,5-tetraphenylphenyl moiety: effective ligands in palladium-catalyzed transformations of aryl chlorides," Organometallics, vol. 25, no. 19, pp. 4665-4669, 2006.

[48] Q. Zhao, C. Li, C. H. Senanayake, and W. Tang, "An efficient method for sterically demanding Suzuki-Miyaura coupling reactions," Chemistry -A European Journal, vol. 19, no. 7, pp. 2261-2265, 2013.

[49] P. J. Milner, T. J. Maimone, M. Su, J. Chen, P. Müller, and S. L. Buchwald, "Investigating the dearomative rearrangement of biaryl phosphine-ligated $\mathrm{Pd}(\mathrm{II})$ complexes," Journal of the American Chemical Society, vol. 134, no. 48, pp. 19922-19934, 2012.

[50] M. Su and S. L. Buchwald, "A bulky biaryl phosphine ligand allows for palladium-catalyzed amidation of five-membered heterocycles as electrophiles," Angewandte Chemie-International Edition, vol. 51, no. 19, pp. 4710-4713, 2012.

[51] K. Kapłon, O. M. Demchuk, and K. M. Pietrusiewicz, "The DFT study on racemisation of atropisomeric biaryls," Current Chemistry Letters, vol. 4, no. 4, pp. 145-152, 2015.

[52] Y. Zhao and D. G. Truhlar, "The M06 suite of density functionals for main group thermochemistry, thermochemical kinetics, noncovalent interactions, excited states, and transition elements: two new functionals and systematic testing of four M06-class functionals and 12 other functionals," Theoretical Chemistry Accounts, vol. 120, no. 1-3, pp. 215-241, 2008.

[53] M. J. Frisch, G. W. Trucks, H. B. Schlegel et al., Gaussian 09. Revision A.1, Gaussian, Inc., Wallingford, Conn, USA, 2009.

[54] Y. Zhao and D. G. Truhlar, "Density functionals with broad applicability in chemistry," Accounts of Chemical Research, vol. 41, no. 2, pp. 157-167, 2008.

[55] R. Jasiński, "Searching for zwitterionic intermediates in Hetero Diels-Alder reactions between methyl $\alpha$,p-dinitrocinnamate and vinyl-alkyl ethers," Computational and Theoretical Chemistry, vol. 1046, pp. 93-98, 2014.

[56] O. M. Demchuk, R. Jasiński, and K. M. Pietrusiewicz, "New insights into the mechanism of reduction of tertiary phosphine oxides by means of phenylsilane," Heteroatom Chemistry, vol. 26, no. 6, pp. 441-448, 2015.

[57] R. Jasiński, "Molecular mechanism of thermal decomposition of fluoronitroazoxy compounds: DFT computational study," Journal of Fluorine Chemistry, vol. 160, pp. 29-33, 2014.

[58] R. Jasiński, E. Dresler, M. Mikulska, and D. Polewski, “[3+2] Cycloadditions of 1-halo-1-nitroethenes with (Z)-C- $(3,4,5-$ trimethoxyphenyl)-N-methyl-nitrone as regio- and stereocontrolled source of novel bioactive compounds: preliminary studies," Current Chemistry Letters, vol. 5, pp. 123-128, 2016.

[59] V. Barone, M. Cossi, and J. Tomasi, "Geometry optimization of molecular structures in solution by the polarizable continuum model," Journal of Computational Chemistry, vol. 19, no. 4, pp. 404-417, 1998.

[60] V. V. Grushin and H. Alper, "The existence and stability of mononuclear and binuclear organopalladium hydroxo complexes, $\left[\left(\mathrm{R}_{3} \mathrm{P}\right)_{2} \mathrm{Pd}(\mathrm{R} \prime)(\mathrm{OH})\right]$ and $\left[\left(\mathrm{R}_{3} \mathrm{P}\right)_{2} \mathrm{Pd}_{2}(\mathrm{R} /)_{2}(\mu-\mathrm{OH})_{2}\right]$," Organometallics, vol. 15, no. 24, pp. 5242-5245, 1996.

[61] V. V. Grushin and H. Alper, "Alkali-induced disproportionation of palladium(II) tertiary phosphine complexes, $\left[\mathrm{L}_{2} \mathrm{PdCl}_{2}\right]$, to LO and palladium(0). Key intermediates in the biphasic carbonylation of ArX catalyzed by $\left[\mathrm{L}_{2} \mathrm{PdCl}_{2}\right]$," Organometallics, vol. 12, no. 5, pp. 1890-1901, 1993.

[62] J. P. Stambuli, C. D. Incarvito, M. Bühl, and J. F. Hartwig, "Synthesis, structure, theoretical studies, and ligand exchange reactions of monomeric, T-Shaped Arylpalladium(II) Halide 
complexes with an additional, weak agostic interaction," Journal of the American Chemical Society, vol. 126, no. 4, pp. 1184-1194, 2004.

[63] B. P. Fors, D. A. Watson, M. R. Biscoe, and S. L. Buchwald, "A highly active catalyst for Pd-catalyzed amination reactions: cross-coupling reactions using aryl mesylates and the highly selective monoarylation of primary amines using aryl chlorides," Journal of the American Chemical Society, vol. 130, no. 41, pp. 13552-13554, 2008.

[64] T. J. Maimone, P. J. Milner, T. Kinzel, Y. Zhang, M. K. Takase, and S. L. Buchwald, "Evidence for in situ catalyst modification during the Pd-catalyzed conversion of aryl triflates to aryl fluorides," Journal of the American Chemical Society, vol. 133, no. 45, pp. 18106-18109, 2011.

[65] A. A. C. Braga, G. Ujaque, and F. Maseras, "A DFT study of the full catalytic cycle of the Suzuki-Miyaura cross-coupling on a model system," Organometallics, vol. 25, no. 15, pp. 3647-3658, 2006.

[66] T. Nishikata, Y. Yamamoto, and N. Miyaura, "1,4-Addition of arylboronic acids and arylsiloxanes to $\alpha, \beta$-unsaturated carbonyl compounds via transmetalation to dicationic palladium(II) complexes," Organometallics, vol. 23, no. 18, pp. 43174324, 2004. 

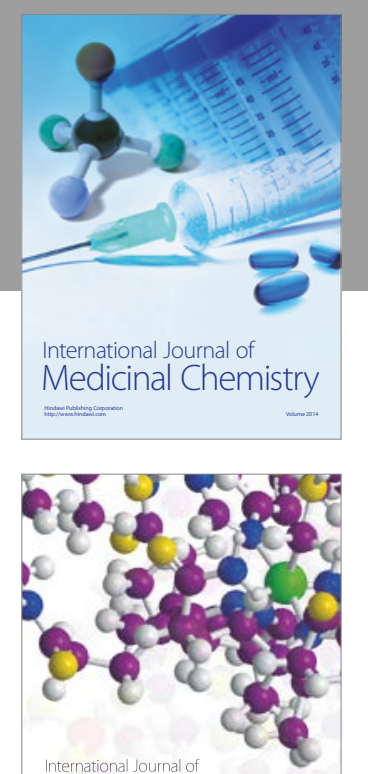

Carbohydrate Chemistry

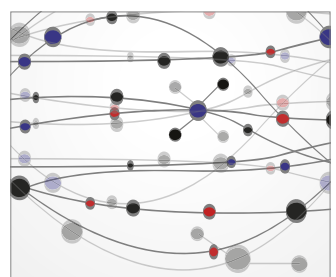

The Scientific World Journal
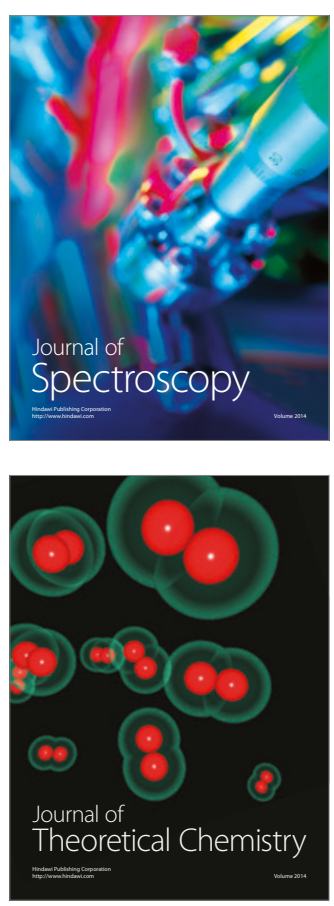
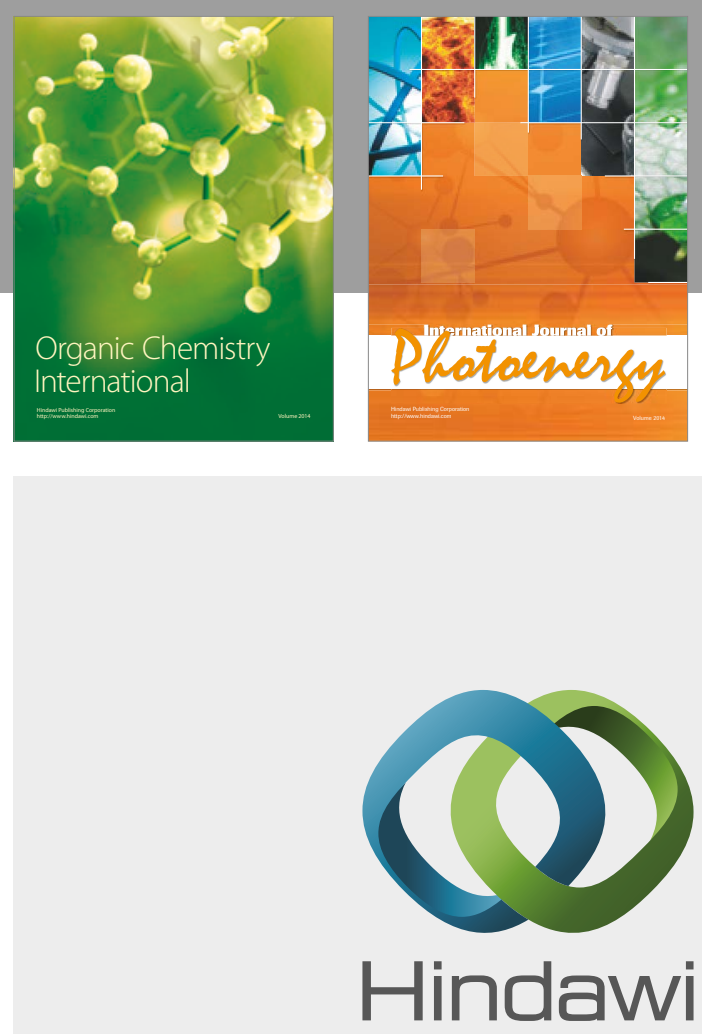

Submit your manuscripts at

https://www.hindawi.com

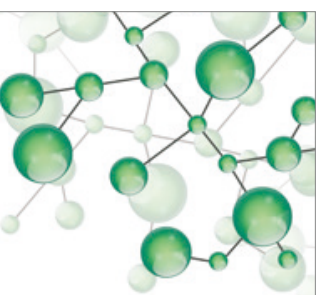

International Journal of

Inorganic Chemistry



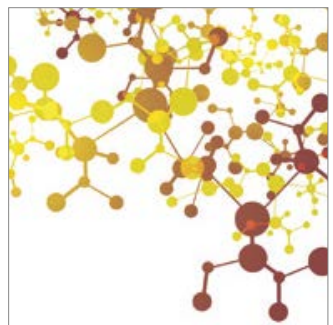

Applied Chemistry

